Article

\title{
Design and Validation of Disturbance Rejection Dynamic Inverse Control for a Tailless Aircraft in Wind Tunnel
}

\author{
Bowen Nie ${ }^{1,2, *(\mathbb{D})}$, Zhitao Liu ${ }^{2}$, Tianhao Guo ${ }^{2, *(\mathbb{D}}$, Litao Fan ${ }^{2}$, Hongxu Ma ${ }^{1}$ and Olivier Sename $^{3}$ (D) \\ 1 College of Intelligence Science and Technology, National University of Defense Technology, \\ Changsha 410073, China; mhx1966@163.com \\ 2 Low Speed Aerodynamics Institute, China Aerodynamics Research and Development Center, \\ Mianyang 621000, China; liuzhitao@cardc.cn (Z.L.); litaofan_cardc@outlook.com (L.F.) \\ 3 Grenoble INP (Institute of Engineering, Université Grenoble-Alpes), CNRS, GIPSA-Lab, \\ 38000 Grenoble, France; olivier.sename@gipsa-lab.grenoble-inp.fr \\ * Correspondence: niebowen_cardc@outlook.com (B.N.); guotianhao@nudt.edu.cn (T.G.)
}

Citation: Nie, B.; Liu, Z.; Guo, T. Fan, L.; Ma, H.; Sename, O. Design and Validation of Disturbance Rejection Dynamic Inverse Control for a Tailless Aircraft in Wind Tunnel. Appl. Sci. 2021, 11, 1407. https:// doi.org/10.3390/app11041407

Academic Editor: Ruxandra

Mihaela Botez

Received: 29 December 2020

Accepted: 1 February 2021

Published: 4 February 2021

Publisher's Note: MDPI stays neutral with regard to jurisdictional claims in published maps and institutional affiliations.

Copyright: (c) 2021 by the authors. Licensee MDPI, Basel, Switzerland. This article is an open access article distributed under the terms and conditions of the Creative Commons Attribution (CC BY) license (https:// creativecommons.org/licenses/by/ $4.0 /)$

\begin{abstract}
This paper focuses on the design of a disturbance rejection controller for a tailless aircraft based on the technique of nonlinear dynamic inversion (NDI). The tailless aircraft model mounted on a three degree-of-freedom (3-DOF) dynamic rig in the wind tunnel is modeled as a nonlinear affine system subject to mismatched disturbances. First of all, a baseline NDI attitude controller is designed for sufficient stability and good reference tracking performance of the nominal system. Then, a nonlinear disturbance observer (NDO) is supplemented to the baseline NDI controller to estimate the lumped disturbances for compensation, including unmodeled dynamics, parameter uncertainties, and external disturbances. Mathematical analysis demonstrates the convergence of the employed NDO and the resulting closed-loop system. Furthermore, an anti-windup modification is applied to the NDO for control performance preserving in the presence of actuator saturation. Subsequently, the designed control schemes are preliminarily validated and compared via simulations. The baseline NDI controller demonstrates satisfactory attitude tracking performance in the case of nominal simulation; the NDO augmented NDI controller presents significantly improved ability of disturbance rejection when compared with the baseline NDI controller in the case of robust simulation; the anti-windup modified scheme, rather than the baseline NDI controller nor the NDO augmented NDI controller, can preserve the closed-loop performance in the case of actuator saturation. Finally, the baseline NDI scheme and the NDO augmented NDI scheme are implemented and further validated in the wind tunnel flight tests, which demonstrate that the experimental results are in good agreement with that of the simulations.
\end{abstract}

Keywords: tailless aircraft; nonlinear dynamic inversion; disturbance observer; anti-windup; flight tests; wind tunnel

\section{Introduction}

Tailless aircraft configurations have gained considerable attention due to the inherent increase in stealth and decreases in weight and drag [1,2]. However, flight control law design for the tailless aircraft is challenging due to the multiaxis instabilities, the insufficient yaw control power, the inaccurate control-oriented modeling, and the adverse external disturbances $[1,3,4]$. Critical flight control research problems for tailless aircraft exist in yaw departure and recovery [5,6], multivariable control for good flying and handling qualities [7-12], reconfigurable control for failure or damage tolerance [13-17], thrust vectoring for envelope expansion [18,19], etc.

In previous aviation industry practices, nonlinear dynamic inversion (NDI) has played an important role in the field of tailless aircraft control law design $[3,8,9,20]$, which provides a nice compromise between controller complexity and performance. NDI is a nonlinear control approach that cancels the system nonlinearity using an onboard dynamic model 
and feedback. The resulting dynamics of selected control variables are globally reduced to integrators across the operating regimes. Hence, simple controllers without gain schedule are adequate to regulate the control variables for desirable closed-loop dynamics [21]. In principle, a perfect knowledge of the system dynamics across the entire flight envelope is required to achieve an exact dynamic cancellation. However, such a requirement is almost impossible to meet in reality due to modeling simplifications, computational errors, and external disturbances [22,23]. Particularly, for the tailless aircraft, uncertainties and disturbances come from the following possible sources: aerodynamic and propulsive approximations, neglected control effector interactions, neglected vehicle elasticity, unmodeled actuator and sensor dynamics, time delay in the feedback path, and wind gust [9]. Besides, there are higher levels of model errors in case of failures, damage, or highly nonlinear phenomena [24]. Intuitively, to overcome the potential robustness issues, flight control researchers employ $\mu$ synthesize, adaptive neural network to construct a robust outer loop for the NDI controller of the tailless aircrafts such as the ICE (innovative control effector) $[8,9]$ and the X-36 $[16,17]$. Although the robustness of these techniques is superior to the regular NDI, not all the uncertainties nor the control signal constraints are taken into account [25], which are inevitably present in the real flight context of tailless aircraft. Meanwhile, to provide sufficient control effort to suppress the effects of the disturbances, such robust methods tend to have large feedback gains [26]. Consequently, a possible closed-loop performance reduction is caused by the conservative design of the gain factors [27].

An alternative solution is based on a composite control structure, including a baseline NDI controller for the desired performance specifications of the nominal system and a nonlinear disturbance observer (NDO) for robustness enhancement of the closed-loop system. The fundamental idea of NDO is to bring together all the internal uncertainties, external disturbances, parameter variations, and unmodeled dynamics as lumped disturbances [26], which are always mismatched and cannot be completely counteracted through control input channels [28]. Taking the partially known nonlinear dynamics into account, an appropriately designed NDO can be employed to reconstruct an inverse model of the actual system, and estimate the nonlinear lumped disturbances by using the baseline NDI control input and the system output. As described in ref $[25,28]$, it is feasible to remove the influence of lumped disturbances from the system output variables in the steady-state and reduce the influence on transient performance with a composite controller involving the NDI and NDO. The NDO employed in this paper is firstly proposed by Chen with rigorous stability analysis of both the NDO and the closed-loop system [29], and then widely applied to the field of flight control, such as the longitudinal autopilot of a missile [30], the longitudinal tracking of an air-breathing hypersonic vehicle [27], the attitude control of a spacecraft [31], etc. It appears that such NDO based control methods can lead to significant improvement of the disturbance rejection ability of an existing controller without scarifying the nominal performance. However, to the authors' knowledge, the existing literatures on NDO based NDI (NDI-DO) control of tailless aircraft are rare. Though a primitive NDI-DO controller has been designed for a tailless aircraft and numerically validated in ref. [32], experimental implementation and flight validation are to be carried out.

As is well known, another main weakness of NDI is the requirement of the plant's input distribution matrix to be invertible. However, it is often the case that the input distribution matrix becomes "almost" singular for some states and hence may lead to excessively large control activities [33]. As deflection range and rate limitations are inevitably present in physical actuated surfaces, aggressively piloted maneuvers of aircraft may yield actuator saturation and associated degradation of closed-loop performance or even loss of stability [34]. A favorable solution in industry and academia to address the actuator saturation is the so-called anti-windup (AW) techniques, in which an existing controller is augmented with an additional element that only becomes active during saturation [35]. In ref. [25], a classic static AW scheme is added to the baseline controller of a tailless unmanned aerial vehicle (UAV) allowing for windup attenuation and nominal performance recovery in 
the absence of saturation. This paper extends the work of ref. [25] to the NDI setting and nonlinear case.

The remainder of this paper is structured as follows. Section 2 provides the preliminaries including a brief introduction to the tailless aircraft, the experimental setup and the mathematical modeling. In Section 3, the equations of angular motions are reformulated in the form of a nonlinear affine system for application of the NDI control scheme, which is then augmented with an NDO to improve the ability of disturbance rejection and further modified for anti-windup enhancement in the presence of actuator saturation. In Section 4, the designed baseline NDI controller, NDI-DO controller, and anti-windup modified controller (NDI-AW) are validated and compared in the context of nonlinear simulations. In Section 5, both the baseline NDI scheme and the NDI-DO scheme are implemented for free flight tests in the wind tunnel, in which the NDI-DO scheme demonstrates the superior ability of disturbance rejection in contrast with the baseline NDI scheme. Finally, a conclusion is provided in Section 6.

\section{Preliminaries}

\subsection{Tailless Aircraft Experimental Setup}

The studied tailless aircraft is of the medium-aspect-ratio and blended-wing-body configuration as shown in Figure 1. There are eight individually driven control surfaces, which could realize the traditionally defined control deflections, i.e., the elevator, the aileron and the rudder. The elevators are classified in left and right having positive deflection when turning downward, the ailerons are also classified left and right having positive deflection when the left surface goes up and the right one goes down. The split drag rudders (SDRs), each one positioned on one side of the wing, are composed of two deferential surfaces: a trailing-wing flap and a mid-wing spoiler. The positive deflection of the rudder is achieved when the left SDR splits symmetrically and the right one keeps at zero.

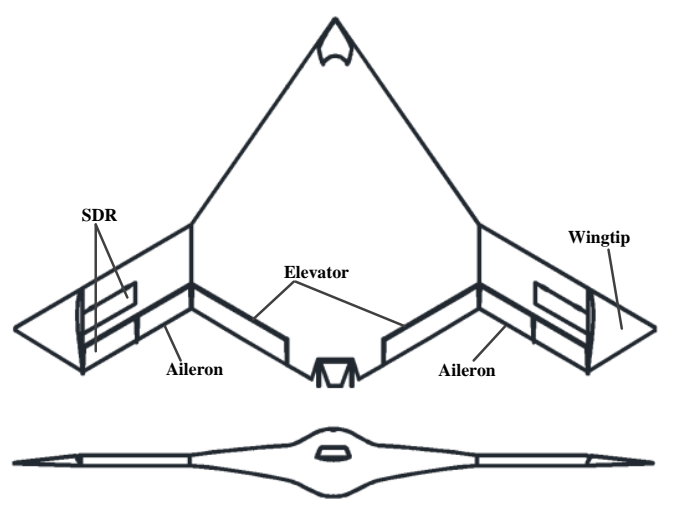

Figure 1. Layout of the tailless aircraft.

From a flight test point of view, the wind tunnel model should be geometrically and dynamically similar to the full-scale aircraft. Hence, a $10 \%$ scaled model was fabricated with carbon fiber and aluminum alloy. The physical parameters, including the characteristic size, mass, and inertia, are carefully tuned as listed in Table 1. A spherical joint is selected to connect a vertical support rig to the airframe at the center of gravity (CG), which frees the aircraft's rotational motions (roll/pitch: $\pm 40^{\circ}$, yaw: $\pm 180^{\circ}$ ) and eliminates the translational motions, as shown in Figure 2. The physical parameters of the scaled model are listed in Table 1 . The model is equipped with not only the surface actuators, but also the sensors including two vanes for angle of attack $(\alpha)$ and angle of sideslip $(\beta)$, an inertial measurement unit (IMU) for angular rates $(p, q, r)$, and an attitude and heading reference system (AHRS) for Euler angles $(\phi, \theta, \psi)$. A flight computer is employed for the implementation of control laws and data acquisition $(100 \mathrm{~Hz})$ using the technique of rapid control system prototyping. For simplicity, the flight computer is placed outside the wind tunnel test section and wired to the onboard avionics. A "pilot" is responsible for handling the aircraft model with a stick. 
Table 1. Physical properties of the dynamically scaled aircraft model.

\begin{tabular}{ccc}
\hline Name & Symbol & Value \\
\hline Scale ratio & $K_{L}$ & $10 \%$ \\
Span & $\mathrm{b}$ & $2.0 \mathrm{~m}$ \\
Mean chord & $\bar{c}$ & $0.6571 \mathrm{~m}$ \\
Wing area & $\mathrm{S}$ & $0.8742 \mathrm{~m}^{2}$ \\
Mass & $\mathrm{m}$ & $16.85 \mathrm{~kg}$ \\
Moment of inertia & $J_{x}, J_{y}, J_{z}$ & $1.1017,0.7380,1.6920 \mathrm{~kg} \cdot \mathrm{m}^{2}$ \\
\hline
\end{tabular}
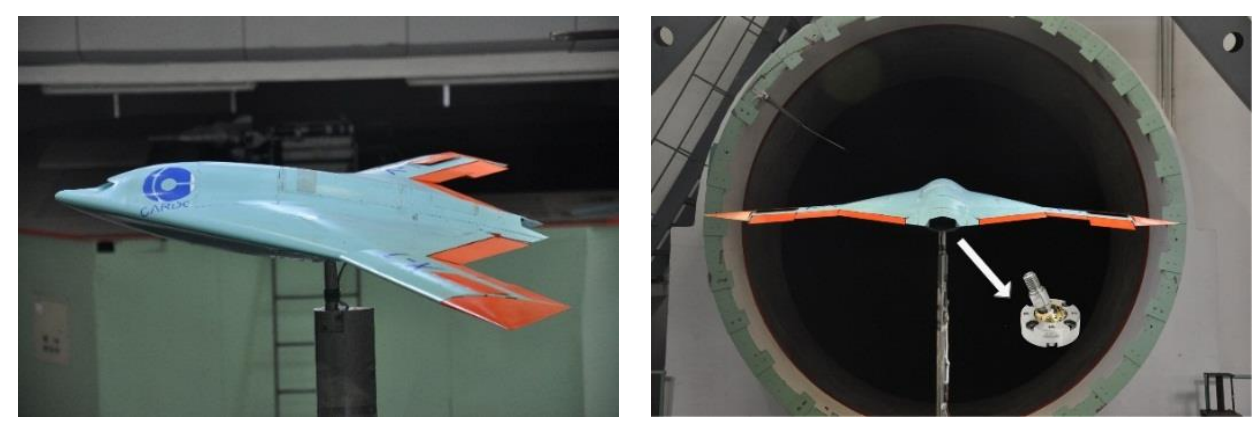

Figure 2. Tailless aircraft model flying on a three degree-of-freedom (3-DOF) dynamic rig in the wind tunnel.

\subsection{Mathematical Modeling}

As the airflow in the wind tunnel test section is exactly horizontal, the experimental setup demonstrates " $1 g$ " level flights, i.e., the flight path angle $(\gamma)$ is always fixed at zero. The flight dynamics of the tailless aircraft model on the rig are modeled as a three degree-of-freedom (3-DOF) angular motion, which has been developed in ref. [32,36,37]. In modeling of this motion, a set of assumptions are made including: the rigid-body aircraft model, the symmetrical distribution of aircraft mass about the $x z$ plane, the negligible aerodynamic interference induced by the rig and the limited dynamic influence of rig friction and support misalignment.

The equations that describe the angular dynamics are derived from Euler's laws in the body-fixed frame as commonly defined for the aircraft [38].

$$
\left[\begin{array}{l}
\dot{p} \\
\dot{q} \\
\dot{r}
\end{array}\right]=J^{-1} M_{B}-J^{-1}\left(\left[\begin{array}{l}
p \\
q \\
r
\end{array}\right] \times J\left[\begin{array}{l}
p \\
q \\
r
\end{array}\right]\right)
$$

where $J=\left[\begin{array}{ccc}J_{x} & 0 & J_{x z} \\ 0 & J_{y} & 0 \\ J_{x z} & 0 & J_{z}\end{array}\right]$.

The CG of the tailless aircraft model coincides well with the aerodynamic reference point. The total external moment acting on the aircraft model $M_{B}$ is the sum of the aerodynamic moments $M_{A}$, the rig friction torque $M_{F}$, and the support misalignment induced torque $M_{G}$.

$$
M_{B}=M_{A}+M_{F}+M_{G}
$$

The kinematic equations of the angular motion are expressed with the aerodynamic angles $\alpha, \beta$, and the bank angle about the velocity vector $(\mu)$ that defines the rotation between the body and wind frame.

$$
\left[\begin{array}{l}
\dot{\alpha} \\
\dot{\beta} \\
\dot{\mu}
\end{array}\right]=\left[\begin{array}{ccc}
-\tan \beta \cos \alpha & 1 & -\tan \beta \sin \alpha \\
\sin \alpha & 0 & -\cos \alpha \\
\sec \beta \cos \alpha & 0 & \sec \beta \sin \alpha
\end{array}\right]\left[\begin{array}{l}
p \\
q \\
r
\end{array}\right]+\left[\begin{array}{l}
d_{21} \\
d_{22} \\
d_{23}
\end{array}\right]
$$


where

$$
\begin{aligned}
& {\left[\begin{array}{l}
d_{21} \\
d_{22} \\
d_{23}
\end{array}\right]=\frac{1}{M V}\left(\left[\begin{array}{c}
W \cos \gamma \cos \mu \sec \beta \\
W \cos \gamma \sin \mu \\
-W \cos \gamma \cos \mu \tan \beta
\end{array}\right]\right.} \\
& \left.+\left[\begin{array}{c}
-L \sec \beta \\
Y \cos \beta \\
L(\tan \beta+\tan \gamma \sin \mu)+Y \tan \gamma \cos \mu \cos \beta
\end{array}\right]\right)
\end{aligned}
$$

It is noted that the last terms in Equation (3), i.e., $\left[\begin{array}{lll}d_{21} & d_{22} & d_{23}\end{array}\right]^{T}$ are the translational terms (aerodynamic lift $L$, aerodynamic side-force $Y$, weight $W$, aircraft mass $M$, and airspeed $V$ ) that influence the rotational motion [39]. As widely accepted [40-42], the influence is negligible when designing the attitude controller.

The aerodynamic forces and moments are expressed as:

$$
\begin{gathered}
F_{A}=\left[\begin{array}{c}
L \\
D \\
Y
\end{array}\right]=\frac{1}{2} \rho V^{2} S\left[\begin{array}{c}
C_{L} \\
C_{D} \\
C_{Y}
\end{array}\right] \\
M_{A}=\left[\begin{array}{c}
l \\
m \\
n
\end{array}\right]=\frac{1}{2} \rho V^{2} S\left[\begin{array}{c}
b \cdot C_{l} \\
\bar{c} \cdot C_{m} \\
b \cdot C_{n}
\end{array}\right]
\end{gathered}
$$

where $D$ is the aerodynamic drag; $l, m, n$ represent the aerodynamic moment of roll, pitch, and yaw; $\rho$ is the air density; $S, b, \bar{c}$ denote the reference wing area, wingspan and mean aerodynamic chord respectively. In practice, the aerodynamic force $\left[\begin{array}{lll}C_{L} & C_{D} & C_{Y}\end{array}\right]^{T}$ and moment $\left[\begin{array}{ccc}C_{l} & C_{m} & C_{n}\end{array}\right]^{T}$ coefficients can be approximated and formulated as the following form [32,37]:

$$
\begin{aligned}
& C_{L}=C_{L 0}(\alpha, \beta)+\Delta C_{L_{\delta_{e}}}(\alpha) \delta_{e}+\Delta C_{L_{\delta_{a}}}(\alpha, \beta) \delta_{a} \\
& \quad+\Delta C_{L_{\delta_{r}}}(\alpha, \beta) \delta_{r}+d_{C_{L}} \\
& C_{D}=C_{D 0}(\alpha, \beta)+\Delta C_{D_{\delta_{e}}}(\alpha) \delta_{e}+\Delta C_{D_{\delta_{a}}}(\alpha, \beta) \delta_{a} \\
& \quad+\Delta C_{D_{\delta_{r}}}(\alpha, \beta) \delta_{r}+d_{C_{D}} \\
& C_{Y}=C_{Y 0}(\alpha, \beta)+\Delta C_{Y_{\delta_{a}}}(\alpha, \beta) \delta_{a}+\Delta C_{Y_{\delta_{r}}}(\alpha, \beta) \delta_{r} \\
& \quad+d_{C_{Y}} \\
& C_{l}=C_{l 0}(\alpha, \beta)+\Delta C_{l_{\delta_{a}}}(\alpha, \beta) \delta_{a}+\Delta C_{l_{\delta_{r}}}(\alpha, \beta) \delta_{r} \\
& \quad+\hat{C}_{l_{p}}(\alpha) \hat{p}+\hat{C}_{l_{r}}(\alpha) \hat{r}+d_{C_{l}} \\
& C_{m}=C_{m 0}(\alpha)+\Delta C_{m_{\delta_{e}}}(\alpha) \delta_{e}+\Delta C_{m_{\delta_{a}}}(\alpha, \beta) \delta_{a} \\
& \quad+\hat{C}_{m_{q}}(\alpha) \hat{q}+d_{C_{m}} \\
& C_{n}=C_{n 0}(\alpha, \beta)+\Delta C_{n_{\delta_{a}}}(\alpha, \beta) \delta_{a}+\Delta C_{n_{\delta_{r}}}(\alpha, \beta) \delta_{r} \\
& +\hat{C}_{n_{p}}(\alpha) \hat{p}+\hat{C}_{n_{r}}(\alpha) \hat{r}+d_{C_{n}}
\end{aligned}
$$

where $\delta_{e}, \delta_{a}, \delta_{r}$ represent the deflection of elevator, aileron and rudder respectively; the normalized body rates are defined as $\hat{p}=p b / 2 V, \hat{q}=q \bar{c} / 2 \mathrm{~V}$, and $\hat{r}=r b / 2 \mathrm{~V}$. Note that the tailless aircraft takes the SDR as the rudder, which is introduced in Section 2.1.

One can see that the aerodynamic force and moment coefficients are described as a function of the aerodynamic angles, the surface deflections, angular rates, and airspeed. The baseline components of $C_{i 0}, i=L, D, Y, l, m, n$ and the incremental components of the surface effectiveness $\Delta C_{i_{j}}, j=\delta_{e}, \delta_{a}, \delta_{r}$ are obtained in the static wind-tunnel tests [36]. The dynamic derivatives of $\hat{C}_{i_{k}}, k=p, q, r$ are measured via the forced-oscillation tests in the wind tunnel [36]. The error components of $d_{C_{i}}$ are the sums of aerodynamic simplifications 
and test errors. The resulting aerodynamic database are rearranged and stored in the form of look-up tables.

\section{Disturbance Rejection Dynamic Inverse Control}

In this section, the NDI control method will be applied to design an attitude controller for the tailless aircraft model in the presence of mismatched disturbances.

\subsection{Problem Formulation and Control Objective}

For NDI controller design, the equations of angular motions are rewritten in the form of a nonlinear affine system:

$$
\begin{aligned}
& \left\{\begin{array}{c}
\dot{x}_{1}=f\left(x_{1}, x_{2}\right)+g\left(x_{1}, x_{2}\right) u+d_{1} \\
\dot{x}_{2}=h\left(x_{1}, x_{2}\right)+d_{2}
\end{array}\right. \\
& y=x_{2}
\end{aligned}
$$

with the fast states $x_{1}=[p, q, r]^{T}$, the slow states $x_{2}=[\alpha, \beta, \mu]^{T}$, the input vector $u=\left[\delta_{a}, \delta_{e}, \delta_{r}\right]^{T}$, the output vector $y$, and the mismatched disturbances of $d_{1}, d_{2}$. The nonlinear behavior of the system lies in the continuous vector functions of $f\left(x_{1}, x_{2}\right), g\left(x_{1}, x_{2}\right)$ and $h\left(x_{1}, x_{2}\right)$.

$$
\begin{gathered}
f=J^{-1}\left(-x_{1} \times J x_{1}+\left[\begin{array}{c}
Q S b\left(C_{l 0}++\hat{C}_{l_{p}} \hat{p}+\hat{C}_{l_{r}} \hat{r}\right) \\
Q S \bar{c}\left(C_{m 0}+\hat{C}_{m_{q}} \hat{q}\right) \\
Q S b\left(C_{n 0}+\hat{C}_{n_{p}} \hat{p}+\hat{C}_{n_{r}} \hat{r}\right)
\end{array}\right]\right) \\
g=J^{-1}\left[\begin{array}{ccc}
Q S b \Delta C_{l_{\delta_{a}}} & 0 & Q S b \Delta C_{l_{\delta_{r}}} \\
Q S \bar{c} \Delta C_{m_{\delta_{a}}} & Q S \bar{c} \Delta C_{m_{\delta_{e}}} & 0 \\
Q S b \Delta C_{n_{\delta_{a}}} & 0 & Q S b C_{n_{\delta_{r}}}
\end{array}\right] \\
h=\left[\begin{array}{ccc}
-\tan \beta \cos \alpha & 1 & -\tan \beta \sin \alpha \\
\sin \alpha & 0 & -\cos \alpha \\
\sec \beta \cos \alpha & 0 & \sec \beta \sin \alpha
\end{array}\right]\left[\begin{array}{c}
p \\
q \\
r
\end{array}\right]
\end{gathered}
$$

where $Q=\frac{1}{2} \rho V^{2}$ is the dynamic pressure.

Obviously, the matrix $g$ is of rank 3 and, therefore, is invertible; the mismatched disturbance $d_{1}$ consists of the aerodynamic modeling errors as presented in Equations (9)-(11) and the rig induced unmodeled errors as shown in Equation (2); the mismatched disturbance $d_{2}$ mainly results from the neglected dynamics as presented in Equation (3).

In the presence of mismatched disturbances, the control objective is to maintain the attitude of the tailless aircraft model around the trim condition, while also allowing for tracking of a reference command for the states $x_{2}$. As a result, the controller is required to provide not only sufficient stability, and good tracking performance, but also rapid disturbance rejection.

\subsection{Baseline Dynamic Inversion Control Design}

In the absence of the disturbance $d_{1}, d_{2}$, a baseline NDI attitude controller is presented in Figure 3. The fundamental behind the controller configuration is the timescale separation principle. Namely, it is assumed that the attitude dynamics are 10 times faster than the attitude kinematics [43-45]. Consequently, the NDI control law is separated into two control loops: the inner loop for the fast states $p, q, r$ and the outer loop for the slow states $\alpha, \beta, \mu$. 


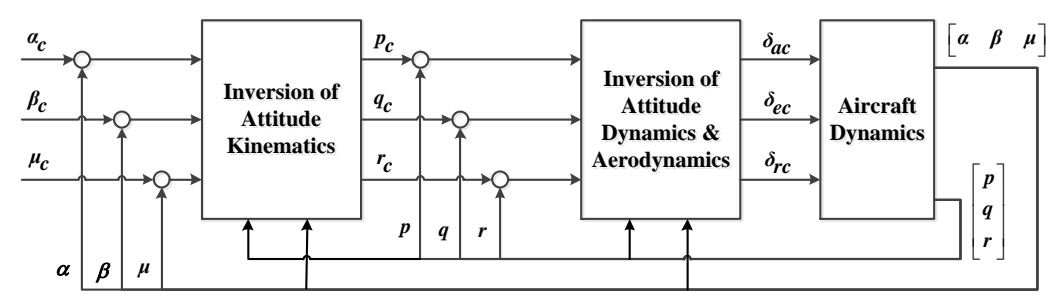

Figure 3. Configuration of the baseline nonlinear dynamic inversion (NDI) controller.

The inner loop is responsible for the inversion of the nonlinear aerodynamic database and attitude dynamics. For the application of NDI, the attitude dynamics are here rewritten in the state-space form:

$$
\begin{gathered}
\dot{x}_{1}=f\left(x_{1}, x_{2}\right)+g\left(x_{1}, x_{2}\right) u \\
y_{1}=x_{1}
\end{gathered}
$$

Recall the approach of feedback linearization, Equation (17) should be successively time differentiated until a relation between the input $u$ and the output $y_{1}$ is found. After one time differentiation, Equation (17) yields

$$
\dot{y}_{1}=\dot{x}_{1}=f\left(x_{1}, x_{2}\right)+g\left(x_{1}, x_{2}\right) u
$$

Substituting the desired differentiated output with the pseudo-control input of Equation (19), the inversion control law of Equation (20) is obtained by inverting Equation (18), the resulting closed inner loop is expressed in Equation (21).

$$
\begin{gathered}
\dot{y}_{1}^{d}=B_{1}\left(x_{1}^{c}-x_{1}\right) \\
u=g^{-1}\left[B_{1}\left(x_{1}^{c}-x_{1}\right)-f\right] \\
\dot{x}_{1}+B_{1}\left(x_{1}-x_{1}^{c}\right)=0
\end{gathered}
$$

where the superscript $d$ represents the desired value, the superscript $c$ represents the command from the outer loop as shown in Figure 3. The bandwidth matrix $B_{1}$, described in Equation (22), is responsible for stabilizing and improving the performance of the closed-loop system when the inversion or the model is not exact.

$$
B_{1}=\left[\begin{array}{ccc}
k_{p} & 0 & 0 \\
0 & k_{q} & 0 \\
0 & 0 & k_{r}
\end{array}\right]
$$

As the steady-state error in the inner loop will be solved by inserting an integrator in the outer loop, $B_{1}$ is only composed of the proportional elements. The gains of $k_{p}, k_{q}, k_{r}$ are tuned to achieve rapid step response without exciting structural modes or exceeding the bandwidth limitations of the actuators [46].

The outer loop performs the inversion of the attitude kinematics equations, which are rewritten as:

$$
\begin{gathered}
\dot{x}_{2}=h\left(x_{1}, x_{2}\right) \\
y_{2}=x_{2}
\end{gathered}
$$

Similar to the inner loop, the output of Equation (24) is not immediately invertible and should be time differentiated once.

$$
\dot{y}_{2}=\dot{x}_{2}=\left[\begin{array}{ccc}
-\tan \beta \cos \alpha & 1 & -\tan \beta \sin \alpha \\
\sin \alpha & 0 & -\cos \alpha \\
\sec \beta \cos \alpha & 0 & \sec \beta \sin \alpha
\end{array}\right] x_{1}
$$




$$
\dot{y}_{2}^{d}=B_{2}\left(x_{2}^{c}-x_{2}\right)
$$

The outer loop control law is computed by substituting Equation (26) into Equation (25) and then inverting it.

$$
x_{1}^{c}=\left[\begin{array}{ccc}
-\tan \beta \cos \alpha & 1 & -\tan \beta \sin \alpha \\
\sin \alpha & 0 & -\cos \alpha \\
\sec \beta \cos \alpha & 0 & \sec \beta \sin \alpha
\end{array}\right]^{-1} B_{2}\left(x_{2}^{c}-x_{2}\right)
$$

resulting in the closed outer loop

$$
\dot{x}_{2}+B_{2}\left(x_{2}-x_{2}^{c}\right)=0
$$

To improve the steady-state performance in the presence of modeling uncertainties, proportional-integral elements (NDI-PI) are used in the bandwidth matrix of $B_{2}$.

$$
B_{2}=\left[\begin{array}{ccc}
k_{P_{\alpha}}+\frac{k_{I_{\alpha}}}{s} & 0 & 0 \\
0 & k_{P_{\beta}}+\frac{k_{I_{\beta}}}{s} & 0 \\
0 & 0 & k_{P_{\mu}}+\frac{k_{I_{\mu}}}{s}
\end{array}\right]
$$

The tuning of $K_{P_{i d x}}$ and $K_{I_{i d x}}, i d x=\alpha, \beta, \mu$ aims for best attitude position tracking performance, while avoiding actuator saturation.

\subsection{Disturbance Observer Enhancement}

In the case of the tailless aircraft model mounted on the 3-DOF rig in the wind tunnel, disturbances do exist as discussed in Equation (12), hence the baseline NDI control law is not necessary to result in a linear and time-invariant closed-loop system anymore. In particular, for the aforementioned inner loop, the closed-loop system of Equation (21) should be reformulated as Equation (31), when adding the mismatched disturbance $d_{1}$ into Equation (16).

$$
\begin{gathered}
\dot{x}_{1}=f\left(x_{1}, x_{2}\right)+g\left(x_{1}, x_{2}\right) u+d_{1} \\
\dot{x}_{1}+B_{1}\left(x_{1}-x_{1}^{c}\right)-d_{1}=0
\end{gathered}
$$

where $d_{1}$ is a lumped disturbance for the overall effect of modeling uncertainties and external disturbances as discussed in Section 2.

From a practical point of view, the lumped disturbance is continuous and bounded, thus satisfying Assumption 1.

Assumption 1. [47] The lumped disturbance and its derivative are bounded and satisfy $\left\|d_{1}\right\| \leq K_{1},\left\|\dot{d}_{1}\right\| \leq K_{2}$, where $K_{1}>0$ and $K_{2}>0$ are specific constants.

The disturbance rejection can be reached by adding integral terms to the bandwidth matrix $B_{1}$ in Equation (22), however, this approach can remove the effect of the nearly constant disturbances in the steady-state but comes at the price of nominal performance degradation $[27,48,49]$. Instead, a nonlinear disturbance observer is designed and patched into the baseline NDI control law of the inner loop as shown in Figure 4. The NDI-DO controller is expected to reject the disturbance while preserving the nominal control performance. 


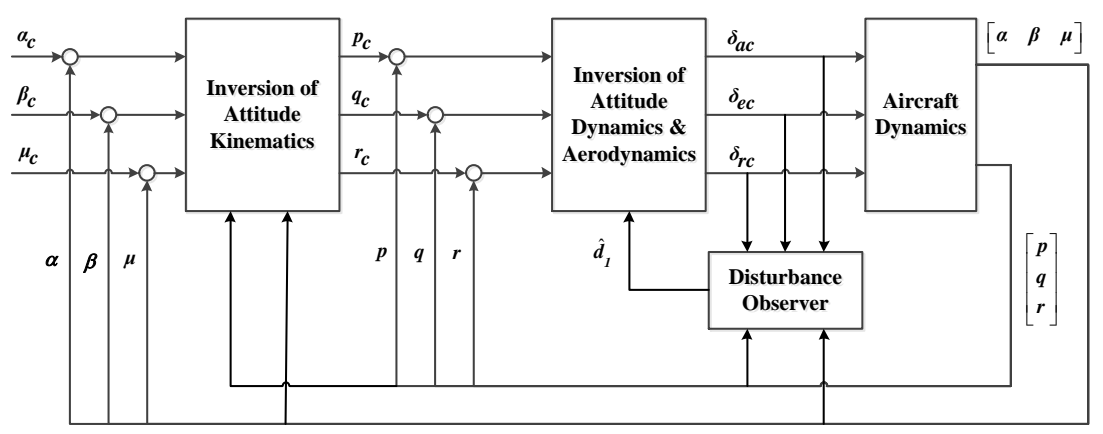

Figure 4. Disturbance observer-enhanced NDI controller.

As reported in ref. $[47,50]$, the nonlinear disturbance observer is given by

$$
\left\{\begin{array}{c}
\dot{z}_{d_{1}}=-l\left(x_{1}\right)\left[\lambda\left(x_{1}\right)+z_{d_{1}}+f\left(x_{1}, x_{2}\right)+g\left(x_{1}, x_{2}\right) u\right] \\
\hat{d}_{1}=z_{d_{1}}+\lambda\left(x_{1}\right)
\end{array}\right.
$$

where $\hat{d}_{1}$ is the estimation of $d_{1}, z_{d_{1}}$ is the internal state vector of the nonlinear observer, and $\lambda\left(x_{1}\right)$ is a nonlinear function to be designed to satisfy $l\left(x_{1}\right)=\partial \lambda\left(x_{1}\right) / \partial x_{1}$.

After the lumped disturbance is estimated by the observer of Equation (32), the disturbance rejection NDI controller yields

$$
u=g^{-1}\left[B_{1}\left(x_{1}^{c}-x_{1}\right)-f-\hat{d}_{1}\right]
$$

It can be readily derived from Equations (30), (32), and (33) that

$$
\begin{gathered}
\dot{e}_{d_{1}}=-l\left(x_{1}\right) e_{d_{1}}+\dot{d}_{1} \\
\dot{e}_{x_{1}}=-B_{1} e_{x_{1}}+e_{d_{1}}
\end{gathered}
$$

where the estimation error is defined as $e_{d_{1}}=d_{1}-\hat{d}_{1}$, and the tracking error is defined as $e_{x_{1}}=x_{1}-x_{1}^{c}$.

Considering the stability of the estimation error and tracking error, the choice of $\lambda\left(x_{1}\right)$ or $l\left(x_{1}\right)$ is appropriate such that the unforced dynamics $\dot{e}_{d_{1}}=-l\left(x_{1}\right) e_{d_{1}}$ is asymptotically stable at $e_{d_{1}}=0[27,47]$.

According to the ref. [25,30,32], a simple and practical choice of $\lambda\left(x_{1}\right)$ is

$$
\lambda\left(x_{1}\right)=L x_{1}=\left[\begin{array}{ccc}
l_{p} & 0 & 0 \\
0 & l_{q} & 0 \\
0 & 0 & l_{r}
\end{array}\right] x_{1}
$$

where $l_{p}, l_{q}$, and $l_{r}$ are positive constants.

In this case, the resulting gain matrix $-l\left(x_{1}\right)=-L$ is Hurwitz, and the estimation error dynamics can be expanded as

$$
e_{d_{1}}=e^{-\left(t-t_{0}\right) L} e_{d_{10}}+\int_{t_{0}}^{t} e^{-(t-\tau) L} \dot{d}_{1}(\tau) d_{\tau}
$$

with $e_{d_{1,0}}=e_{d_{1}}\left(t_{0}\right)$ as the initial estimation error. 
The solution of Equation (37) can be estimated using the bound of $\left\|e^{-\left(t-t_{0}\right) L}\right\| \leq$ $\kappa_{1} e^{-\kappa_{2}\left(t-t_{0}\right)}$ from the Theorem 4.11 of ref. [51].

$$
\begin{aligned}
\left\|e_{d_{1}}\right\| & \leq\left\|e^{-\left(t-t_{0}\right) L}\right\|\left\|e_{d_{1,0}}\right\|+\int_{t_{0}}^{t}\left\|e^{-(t-\tau) L}\right\| \sup _{t_{0} \leq \tau \leq t}\left\|\dot{d}_{1}(\tau)\right\| d_{\tau} \\
& \leq \kappa_{1} e^{-\kappa_{2}\left(t-t_{0}\right)}\left\|e_{d_{1,0}}\right\|+\int_{t_{0}}^{t} \kappa_{1} e^{-\kappa_{2}\left(t-t_{0}\right)} d_{\tau} \sup \left\|\dot{d}_{1}(t)\right\| \\
& \leq \kappa_{1} e^{-\kappa_{2}\left(t-t_{0}\right)}\left\|e_{d_{1,0}}\right\|+\frac{\kappa_{1}}{\kappa_{2}} \sup _{t \geq t_{0}}\left\|\dot{d}_{1}(t)\right\|
\end{aligned}
$$

Thus, the ultimate bound of the estimation error is given by

$$
\underset{t \rightarrow+\infty}{\limsup }\left\|e_{d_{1}}\right\| \leq \frac{\kappa_{1}}{\kappa_{2}} \sup _{t \geq t_{0}}\left\|\dot{d}_{1}(t)\right\|
$$

where $\kappa_{1}$ and $\kappa_{2}$ are positive constants decided by the Hurwitz matrix $-L$.

Under Assumption 1, it is noted from Equation (38) that the zero-input response decays to zero exponentially fast, while the zero-state response is bounded for every bounded input [27,47]. Additionally, Equation (39) shows that the estimation error can be finally regulated into an arbitrarily small neighborhood of zero with sufficiently small $\kappa_{1} / \kappa_{2}$. To do this, positive and sufficiently large elements of the gain matrix in Equation (36) are required to achieve faster observer dynamics than that of the disturbance $[25,27]$.

Similarly, recalling the Hurwitz property of $-B_{1}$, the tracking error can be expressed as

$$
\begin{aligned}
\left\|e_{x_{1}}\right\| & \leq\left\|e^{-\left(t-t_{0}\right) B_{1}}\right\|\left\|e_{x_{1,0}}\right\|+\int_{t_{0}}^{t}\left\|e^{-(t-\tau) B_{1}}\right\| \sup _{t_{0} \leq \tau \leq t}\left\|e_{d_{1}}(\tau)\right\| d_{\tau} \\
& \leq \kappa_{3} e^{-\kappa_{4}\left(t-t_{0}\right)}\left\|e_{x_{1,0}}\right\|+\int_{t_{0}}^{t} \kappa_{3} e^{-\kappa_{4}\left(t-t_{0}\right)} d_{\tau} \sup \left\|e_{d_{1}}(t)\right\| \\
& \leq \kappa_{3} e^{-\kappa_{4}\left(t-t_{0}\right)}\left\|e_{x_{1,0}}\right\|+\frac{\kappa_{3}}{\kappa_{4}} \sup _{t \geq t_{0}}\left\|e_{d_{1}}(t)\right\|
\end{aligned}
$$

From this, it follows that:

$$
\limsup _{t \rightarrow+\infty}\left\|e_{x_{1}}\right\| \leq \frac{\kappa_{1} \kappa_{3}}{\kappa_{2} \kappa_{4}} \sup \left\|\dot{d}_{1}(t)\right\|
$$

where $e_{x_{1,0}}=e_{x_{1}}\left(t_{0}\right)$ denotes the initial value of tracking error and $\kappa_{3}, \kappa_{4}$ are positive constants decided by $-B_{1}$.

The effects of the lumped disturbance on the tracking error is bounded under Assumption 1 and can be mitigated with sufficiently small $\kappa_{1} \kappa_{3} / \kappa_{2} \kappa_{4}$. Namely, it is beneficial to reject the disturbance with larger gains in both the bandwidth matrix $B_{1}$ and the gain matrix $L$.

\subsection{Anti-Windup Modification}

For the tailless aircraft model, the actuators will saturate for surface commands out of the deflection ranges listed in Table 2.

Table 2. Deflection range of the surfaces on the tailless aircraft model.

\begin{tabular}{cccc}
\hline Surface & Notation & Position Bound & Rate Limit \\
\hline Aileron/Elevator & $\delta_{a}, \delta_{e}$ & $\pm 30^{\circ}$ & $\pm 200^{\circ} / \mathrm{s}$ \\
Rudder & $\delta_{r}$ & $\pm 40^{\circ}$ & $\pm 200^{\circ} / \mathrm{s}$ \\
\hline
\end{tabular}

In the presence of actuator saturation, the system of Equation (30) takes the form:

$$
\dot{x}_{1}=f\left(x_{1}, x_{2}\right)+g\left(x_{1}, x_{2}\right) \operatorname{sat}(u)+d_{1}
$$




$$
\operatorname{sat}(u)=\left[\begin{array}{l}
\operatorname{sat}_{\delta_{a}}\left(u_{\delta_{a}}\right) \\
\operatorname{sat}_{\delta_{e}}\left(u_{\delta_{e}}\right) \\
\operatorname{sat}_{\delta_{r}}\left(u_{\delta_{r}}\right)
\end{array}\right]
$$

where $s a t_{j}$ is the saturation operator defined as following:

$$
\operatorname{sat}_{j}\left(u_{j}\right)=\left\{\begin{array}{l}
u_{j}^{\max }, u_{j} \geq u_{j}^{\max } \\
u_{j}, u_{i}^{\min } \leq u_{j} \leq u_{j}^{\max } \\
u_{j}^{\min }, u_{j} \leq u_{j}^{\min }
\end{array}\right.
$$

When saturation is active, the controller of Equation (33) exhibits windup, which could lead to significant performance degradation and even instability of the closed-loop system. To attenuate the effect of windup, an anti-windup modification is made to the disturbance observer of Equation (32) referring to ref. [25].

$$
\left\{\begin{array}{c}
\dot{z}_{d_{1}}=-l\left(x_{1}\right)\left[\lambda\left(x_{1}\right)+z_{d_{1}}+f\left(x_{1}, x_{2}\right)+g\left(x_{1}, x_{2}\right) u\right] \\
+K_{s a t}[u-\operatorname{sat}(u)] \\
\hat{d}_{1}=z_{d_{1}}+\lambda\left(x_{1}\right)
\end{array}\right.
$$

where the term of $K_{s a t}$ is an anti-windup gain matrix to be designed.

Thus, using the modified observer of Equation (45) for estimation of the lumped disturbance in Equation (42), we have:

$$
\dot{e}_{d_{1}}=-L e_{d_{1}}+\dot{d}_{1}+\left[l\left(x_{1}\right) g\left(x_{1}, x_{2}\right)-K_{\text {sat }}\right][u-\operatorname{sat}(u)]
$$

The anti-windup gain matrix $K_{\text {sat }}$ can be chosen as the following so that the effect of actuator saturation on the disturbance observer will be removed.

$$
K_{s a t}=l\left(x_{1}\right) g\left(x_{1}, x_{2}\right)
$$

When Equation (47) is substituted into Equation (45), the modified disturbance observer yields

$$
\left\{\begin{array}{c}
\dot{z}_{d_{1}}=-l\left(x_{1}\right)\left[\lambda\left(x_{1}\right)+z_{d_{1}}+f\left(x_{1}, x_{2}\right)\right. \\
\left.+g\left(x_{1}, x_{2}\right) \operatorname{sat}(u)\right] \\
\hat{d}_{1}=z_{d_{1}}+\lambda\left(x_{1}\right)
\end{array}\right.
$$

The architecture of the closed-loop system with the actuator saturation and modified observer (NDI-AW) is as presented in Figure 5. Note that the anti-windup modified disturbance observer is driven by the actual surface deflections rather than the surface commands. Combining the plant dynamics of Equation (42), the inner-loop NDI controller of Equation (33) and the anti-windup modified disturbance observer of Equation (48), it is readily reached that the closed-loop tracking error takes the same form as Equation (35). Hence, the effect of actuator saturation on the closed-loop tracking performance is also removed.

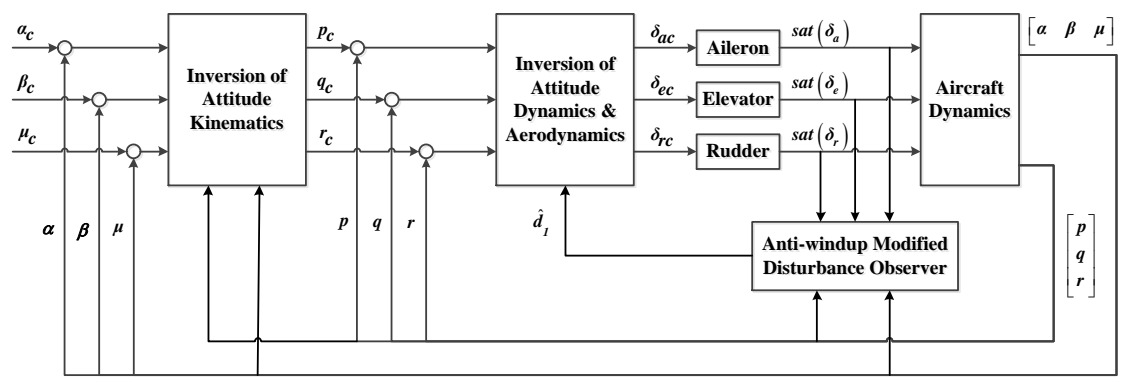

Figure 5. Anti-windup modification of the disturbance observer-enhanced NDI controller. 


\section{Simulation Study}

This section describes the simulation testing of the three control schemes in attitude reference tracking, including the NDI-PI, the NDI-DO, and the NDI-AW. During the simulations, the aircraft model in the wind tunnel as detailed in Section 2 is augmented with second-order actuator dynamics for each surface, considering the deflection saturation in Table 2 and the time delay of $10 \mathrm{~ms}$. The controller and observer gains are given in Table 3, which have been tuned to ensure tracking and robust performance in the presence of significant disturbances as listed in Table 4. For the sake of comparability, the nominal and robust simulations were all performed with the same step inputs on $\alpha_{c}$ and $\mu_{c}$ while minimizing the sideslip angle $\left(\beta_{c}=0\right)$ at the airspeed of $30 \mathrm{~m} / \mathrm{s}$. In contrast, step inputs were also applied to the sideslip angle in the anti-windup simulation.

Table 3. Controller and observer gains.

\begin{tabular}{cccc}
\hline Coefficient & NDI-PI & NDI-DO & NDI-AW \\
\hline$K_{p}, K_{q}, K_{r}$ & $20.0,20.0,10.0$ & $10.0,10.0,5.0$ & $10.0,10.0,5.0$ \\
$K_{P_{\alpha}}, K_{P_{\beta}}, K_{P_{\mu}}$ & $2.0,2.0,2.0$ & $2.0,2.0,2.0$ & $2.0,2.0,2.0$ \\
$K_{I_{\alpha}}, K_{I_{\beta}}, K_{I_{\mu}}$ & $0.1,0.1,0.1$ & $0.2,0.2,0.2$ & $0.2,0.2,0.2$ \\
$l_{p}, l_{q}, l_{r}$ & - & $15.0,15.0,15.0$, & $15.0,15.0,15.0$ \\
\hline
\end{tabular}

Table 4. Distributions for parameters affecting the robustness.

\begin{tabular}{cccc}
\hline Parameter & Distribution & Mean & Standard Deviation \\
\hline Noise of & normal & 0 & $2.0^{\circ}$ \\
$\alpha, \beta, \mu$ & & & $0.4^{\circ} / \mathrm{s}$ \\
Noise of & normal & 0 & $30 \%$ \\
$p, q, r$ & normal & 0 & $5 \mathrm{~mm}$ \\
Bias of $C_{i 0}, \Delta C_{i_{j}}, \hat{C}_{i_{k}}$ & normal & 0 & Mismatch of $\mathrm{CG}$ \\
\hline
\end{tabular}

\subsection{Comparison of the Nominal Performance}

The nominal response of the three controllers to the tracking signal is given in Figure 6. As shown in Figure 6a, the reference signal of $\alpha_{c}$ was designed as a "square" with an amplitude of $5^{\circ}$ and a width of $20 \mathrm{~s}$. Each of the controller tracks the reference command well with a rise time of $1.0 \mathrm{~s}$ and an overshoot of $2 \%$. As presented in Figure $6 \mathrm{~b}$, the reference signal of $\mu_{c}$ was a "doublet" with an amplitude of $5^{\circ}$ and a width of $5 \mathrm{~s}$. The rise time of the three controllers was around $0.8 \mathrm{~s}$. However, there was an overshoot of $4 \%$ for the NDI-PI controller, while the other two controllers experienced no overshoot. In Figure $6 c$, it is observed that $\beta$ tracking error was always smaller than $0.6^{\circ}$, which was the coupling response to the bank maneuvers. Moreover, the estimated lumped disturbances are shown in Figure 6d. Though there were notable estimation mismatches between the NDI-DO and the NDI-AW, the closed-loop performance under the two schemes were close to each other.

\subsection{Comparison of the Robust Performance}

The response of the tailless aircraft model controlled using the NDI-PI, NDI-DO, and NDI-AW with the sensor noise is shown in Figure 7. For comparison, the nominal response of the NDI-DO was also plotted with blue dotted lines. It turns out that the noise was not blown up for the three schemes, i.e., the steady responses of $\alpha, \mu$, and $\beta$ were remarkably influenced by the sensor noise. However, it is to be mentioned that the disturbance observers succeeded to capture the disturbances induced by the bank maneuver as shown in Figure 7d. 


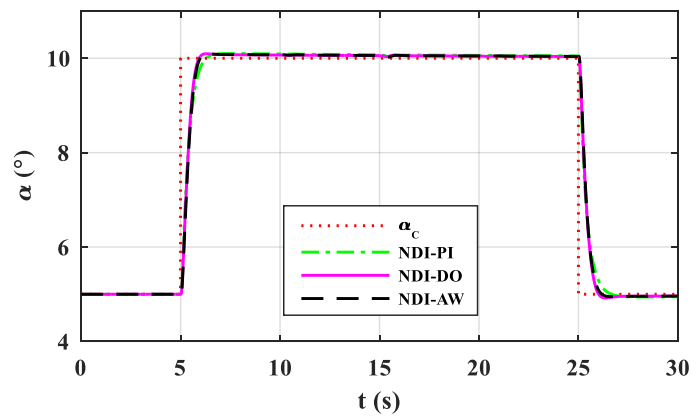

(a) Angle of attack

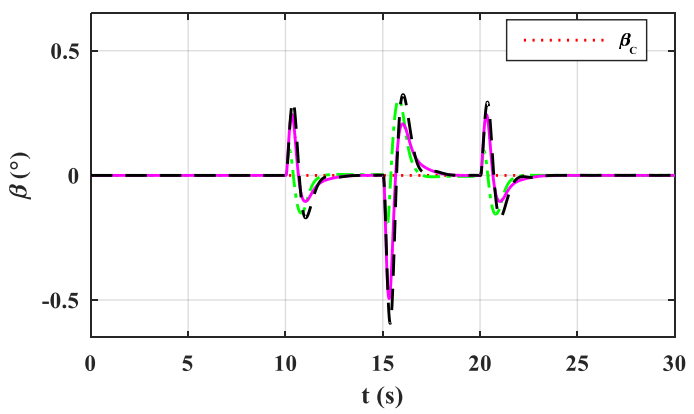

(c) Angle of sideslip

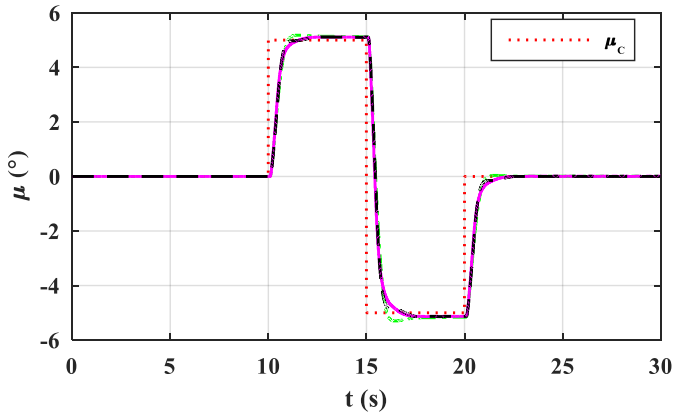

(b) Bank angle about the velocity vector

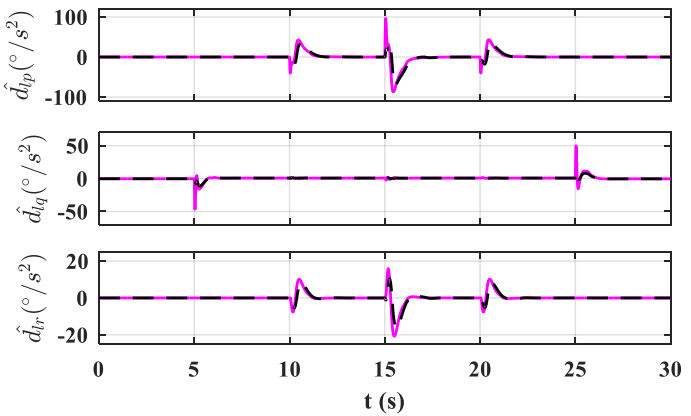

(d) Estimation of the lumped disturbances

Figure 6. The nominal response of the tailless aircraft model controlled using NDI-proportional-integral elements (PI), nonlinear disturbance operator based NDI (NDI-DO), and NDI-anti-windup (AW).

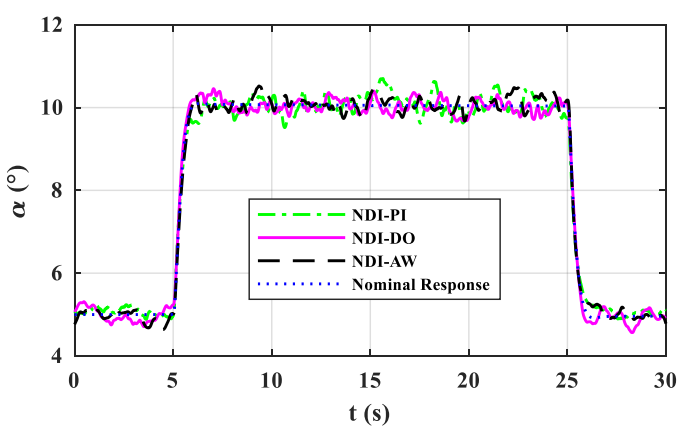

(a) Positions of the aerodynamic surfaces

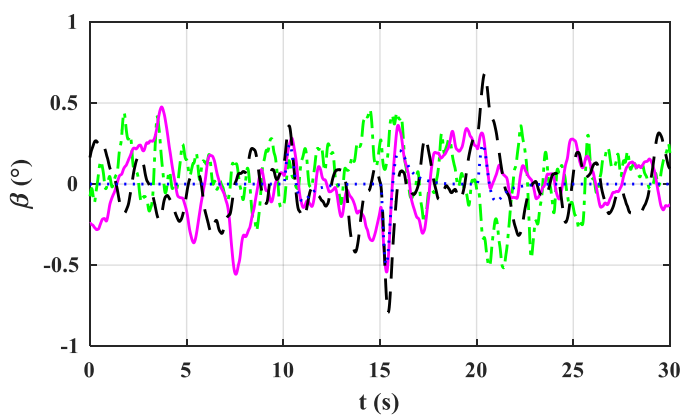

(c) Positions of the aerodynamic surfaces

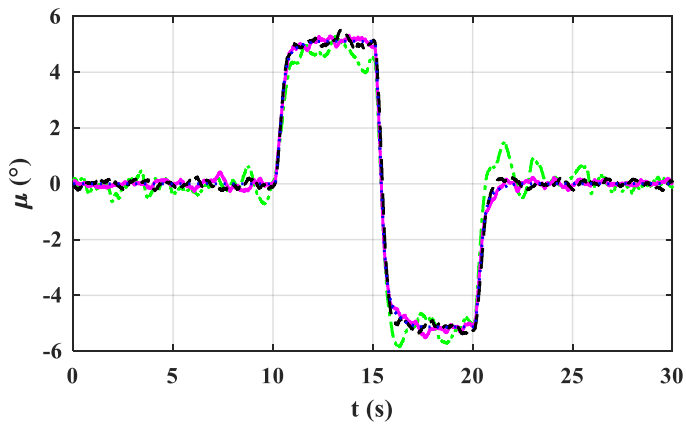

(b) Rates of the aerodynamic surfaces

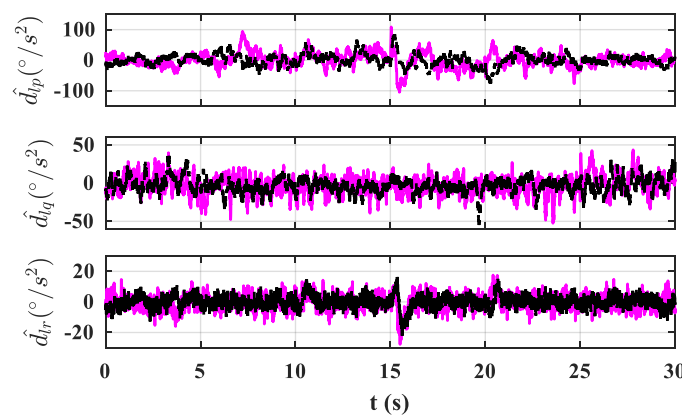

(d) Estimation of the lumped disturbances

Figure 7. Response of the tailless aircraft model controlled using NDI-PI, NDI-DO, and NDI-AW with the sensor noise.

Figure 8 presents the robust simulation testing with the aerodynamic bias and the CG mismatch following the distributions in Table 4. Responses of five realizations in the distribution space are plotted for comparison with the nominal response of the NDI-DO controller. 
It is noted that the NDI-PI controller suffers from the proposed disturbances and the tracking performance is unsatisfactory. As discussed in ref [36], it is the CG mismatch, especially along the aircraft's longitudinal axis, which will bring remarkable external disturbances to the aircraft's flight dynamics. As a result, the step responses of NDI-PI are scattered as shown in Figure 8a,b. In the case of $\alpha$, remarkable response undershoot or overshoot is observed for each realization ranged from about $-34 \%$ to $+68 \%$ of the reference step signal, and the integrators in the outer loop controller of Equation (29) tend to eliminate the steady error gradually. In the case of $\mu$, a significant tracking error is caused not only by the bank maneuver but also by the coupling effect of the pitch maneuver. In the case of $\beta$, the performance is satisfactory with a slightly increased magnitude of coupling error.

Compared with the NDI-PI controller, the NDI-DO and NDI-AW controllers are not sensitive to the aerodynamic biases or the CG mismatch. The $\alpha$ and $\mu$ responses are recovered close to that of the nominal case, except that the overshoots and damping deteriorate marginally, and the coupling influence of $\mu$ maneuver to $\alpha$ and $\beta$ increases slightly. It is the disturbance observers of Equations (32) and (48) that estimate the aerodynamic biases and the CG mismatch as a set of lumped disturbances, respectively, as shown in Figure 8d. Additionally, then, the estimated lumped disturbances are substituted into Equation (33) for dynamic inversion compensation. As a result, the disturbance rejection abilities of NDI-DO and NDI-AW have been improved significantly. Besides, the notable coupling error is observed in $\mu$ and $\beta$ at about $6 \mathrm{~s}$ and $26 \mathrm{~s}$, when the aircraft model nose up or nose down rapidly. As is well known, the magnitude of aerodynamic forces applied to the aircraft varies a lot along with the angle of attack. In the presence of the CG mismatch, significant moment shifts are induced as shown in Figure 8d. Consequently, the tracking performance of the NDI-DO and the NDI-AW controllers decays along with the rapid fluctuations of the lumped disturbances.

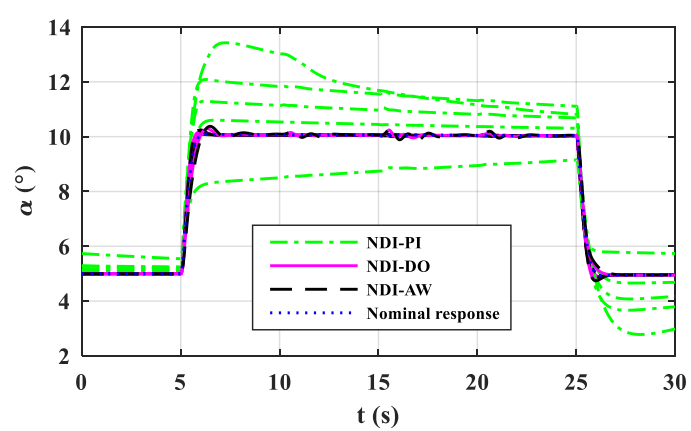

(a) Angle of attack

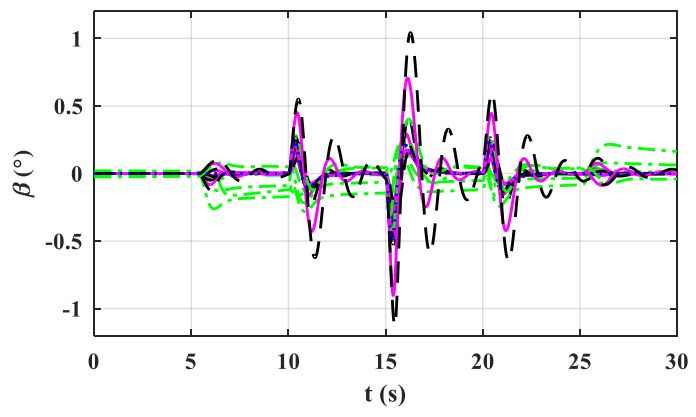

(c) Angle of sideslip

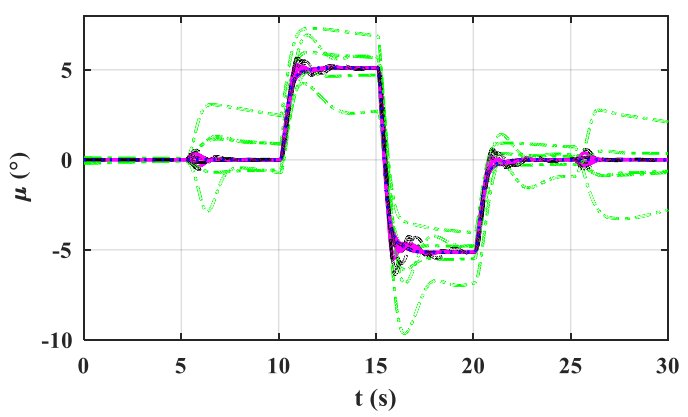

(b) Bank angle about the velocity vector

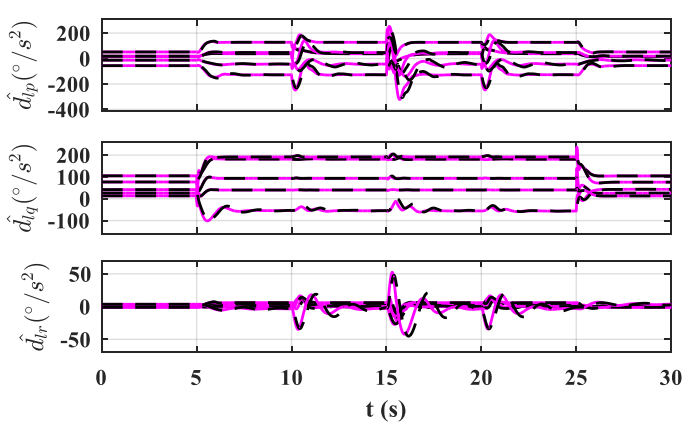

(d) Estimation of the lumped disturbances

Figure 8. Response of the tailless aircraft model controlled using NDI-PI, NDI-DO, and NDI-AW with the aerodynamic bias and the center of gravity (CG) mismatch.

\subsection{Investigation of the Anti-Windup Performance}

In this part, aggressive maneuvers for the longitudinal, lateral, and directional channels are performed with their respective square and doublet reference inputs. The am- 
plitude of the maneuvers is chosen through a trial-and-error approach to ensure that the problem of actuator saturation is excited. For the sake of simplicity, the disturbances listed in Table 4 were turned off for this simulation.

The results are shown in Figure 9 with the corresponding responses of the aircraft model controlled by the three schemes. It turns out that the both the NDI-PI and NDI-DO schemes suffered from the large amplitude maneuvers, while the NDI-AW scheme shows significantly improved performance.

The first remarkable response mismatch of the three schemes is observed during the time from about 10 to 15 s, i.e., the tracking performance of the NDI-PI scheme deteriorated in terms of furious coupling, overshoot, oscillation and steady-error. However, the tracking performances of the other two schemes were satisfactory and close to each other. Such an outcome was in agreement with the prospective effect of the disturbance observer. On one hand, the NDI-DO and the NDI-AW controllers estimated the lumped disturbances using Equations (32) and (48), respectively, which were then compensated using the inner-loop dynamic inversion controller of Equation (33). As a result, the influence of the lumped disturbances to the closed-loop system was mostly rejected by the disturbance observer augmented controllers. On the other hand, though transient saturation was observed for both the NDI-DO and the NDI-AW schemes, the problem of windup was not excited sufficiently to cause the closed-loop performance decay.

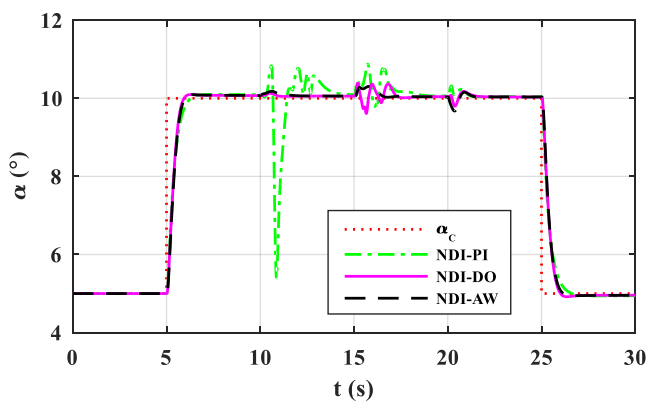

(a) Angle of attack

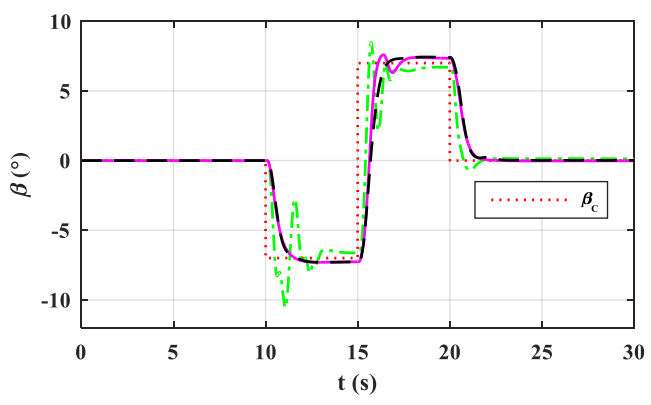

(c) Angle of sideslip
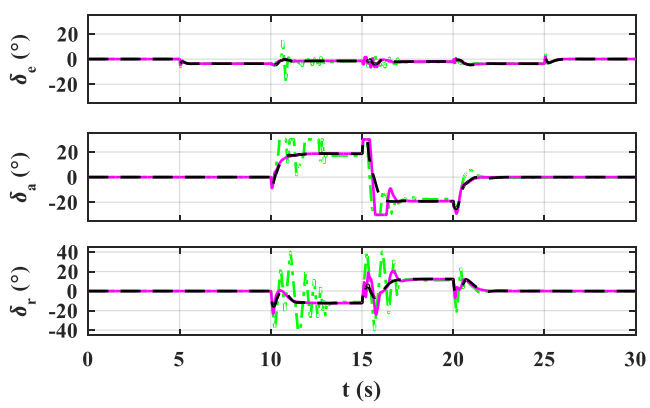

(e) Position of the aerodynamic surfaces

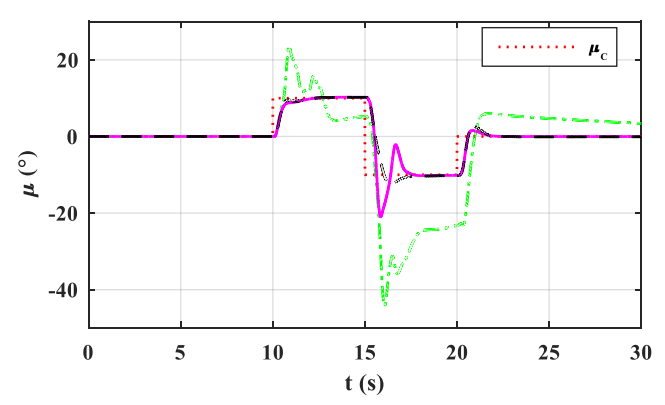

(b) Bank angle about the velocity vector

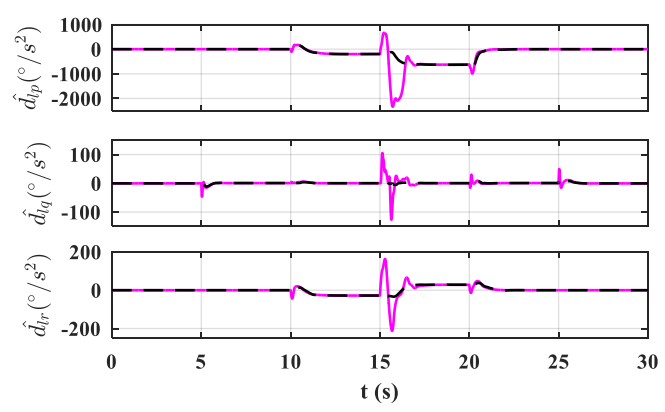

(d) Estimation of the lumped disturbances
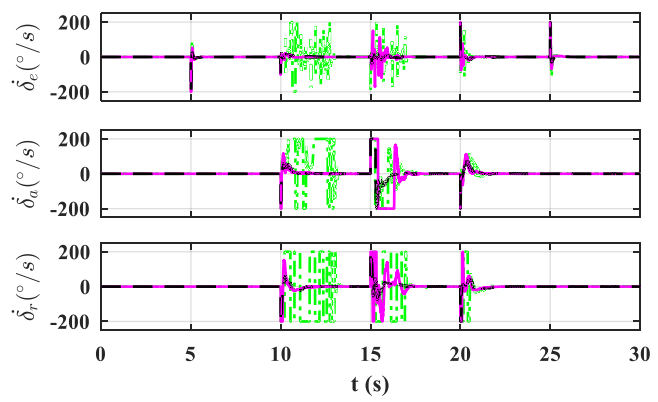

(f) Rate of the aerodynamic surfaces

Figure 9. Response of the tailless aircraft model controlled using NDI-PI, NDI-DO, and NDI-AW with the actuator saturation. 
During the bank and sideslip maneuver from 15 to $20 \mathrm{~s}$, the performance of not only the NDI-PI but also the NDI-DO deteriorated significantly, while the response of the NDI-AW was still satisfactory with marginal overshoot in $\mu$ and coupling error in $\alpha$. Regarding the performance maintenance of the NDI-AW scheme in the presence of actuator saturation, the effect of the anti-windup modified observer was investigated. As soon as the deflections of the aerodynamic surfaces saturate, the anti-windup modification of Equation (48) in the NDI-AW scheme became active, which took the actuator induced delay and error into account. Hence, the deflection saturations induced nonlinear disturbance is estimated and compensated by the NDI-AW scheme, whereas this is not the fact for the NDI-DO scheme. As a result, the estimated lumped disturbance of the NDI-AW in Figure $9 \mathrm{~d}$ was of much smaller magnitude than that of the NDI-DO. Furthermore, according to Equation (39), the estimation error of the disturbance observer was related to the time derivative of the disturbances. Since the lumped disturbance of the NDI-DO consists of the nonlinear, noncontinuous deflection saturations, the resulting estimation error blows up. This explains the performance decay of the NDI-DO scheme.

\section{Experimental Results}

A flight test campaign was conducted in the wind tunnel using the NDI-PI and NDI-DO schemes. Due to the difficulties to sense the actual deflections of the surfaces, the NDI-AW scheme was not implemented in the test. As shown in Figure 10, the same reference inputs as that of the nominal and robust simulations in Section 4 were applied to the aircraft model for multiple times at the wind speed of $20 \mathrm{~m} / \mathrm{s}, 25 \mathrm{~m} / \mathrm{s}$, and $30 \mathrm{~m} / \mathrm{s}$, respectively, to obtain repeatable responses of the aircraft model. The controller was selected and activated via the signal of "NoCtrl" from a switch button of the pilot stick, which is a discrete variable corresponding to the case of open-loop (OFF) with " 0 ", NDI-PI with " 1 ", and NDI-DO with "2". For the sake of controller initialization, switching between the NDI-PI and the NDI-DO was always interpolated with "OFF" for about $1 \mathrm{~s}$. One can note that the attitude responses of the aircraft model under the NDI-PI and NDI-DO were reasonable, except that notable perturbations were observed at around $290 \mathrm{~s}, 630 \mathrm{~s}$ due to step increase of the wind speed, and at about 174 s, 210 s, 347 s, 415 s, and 792 s due to outliers of the IMU sensor.

The experimental data under the NDI-PI and NDI-DO at the wind speed of $30 \mathrm{~m} / \mathrm{s}$ are presented in Figure 11 in comparison to the nominal simulation responses of NDI-DO. For the sake of comparability, the time axis of the experimental data is shifted to be coincident with the simulation, i.e., from 0 to $30 \mathrm{~s}$. One can see that experimental responses agreed well with the simulation, though high-frequency noise has been introduced into the attitude by the sensors. In general, the experimental responses were satisfactory with an overshoot of about $11 \%$ in $\alpha$ under the NDI-DO, an overshoot of about $14 \%$ and a slight decay of damping in $\mu$ under the NDI-PI. Performances of both the NDI-PI and the NDI-DO schemes deteriorated due to the disturbances in the experimental setup. As shown in Figure 11d, the estimated lumped disturbances of NDI-DO in the test shifted and deviated remarkably from that of NDI-DO in the simulation. According to the results and analysis of the robust simulation in Section 4, it is inferred that there were marginal mismatches between the CG of the aircraft model and the rotational center of the support rig. Besides, moderate disturbances may result from the bias and noise of the sensors, the aerodynamic influence of the support rig, the error of aircraft mass and inertia, the fluctuation of wind speed, etc. Compared to the NDI-PI scheme, the disturbance observer augmented scheme of NDI-DO decreases the coupling error in $\alpha$ and $\beta$ during the bank maneuver.

In summary, the experimental results show that both the NDI-PI and the NDI-DO schemes worked well to stabilize and control the attitude of the aircraft model in the wind tunnel tests. The NDI-DO scheme demonstrated slightly improved tracking performance than the NDI-PI scheme in the presence of the disturbances in the experimental setup. 

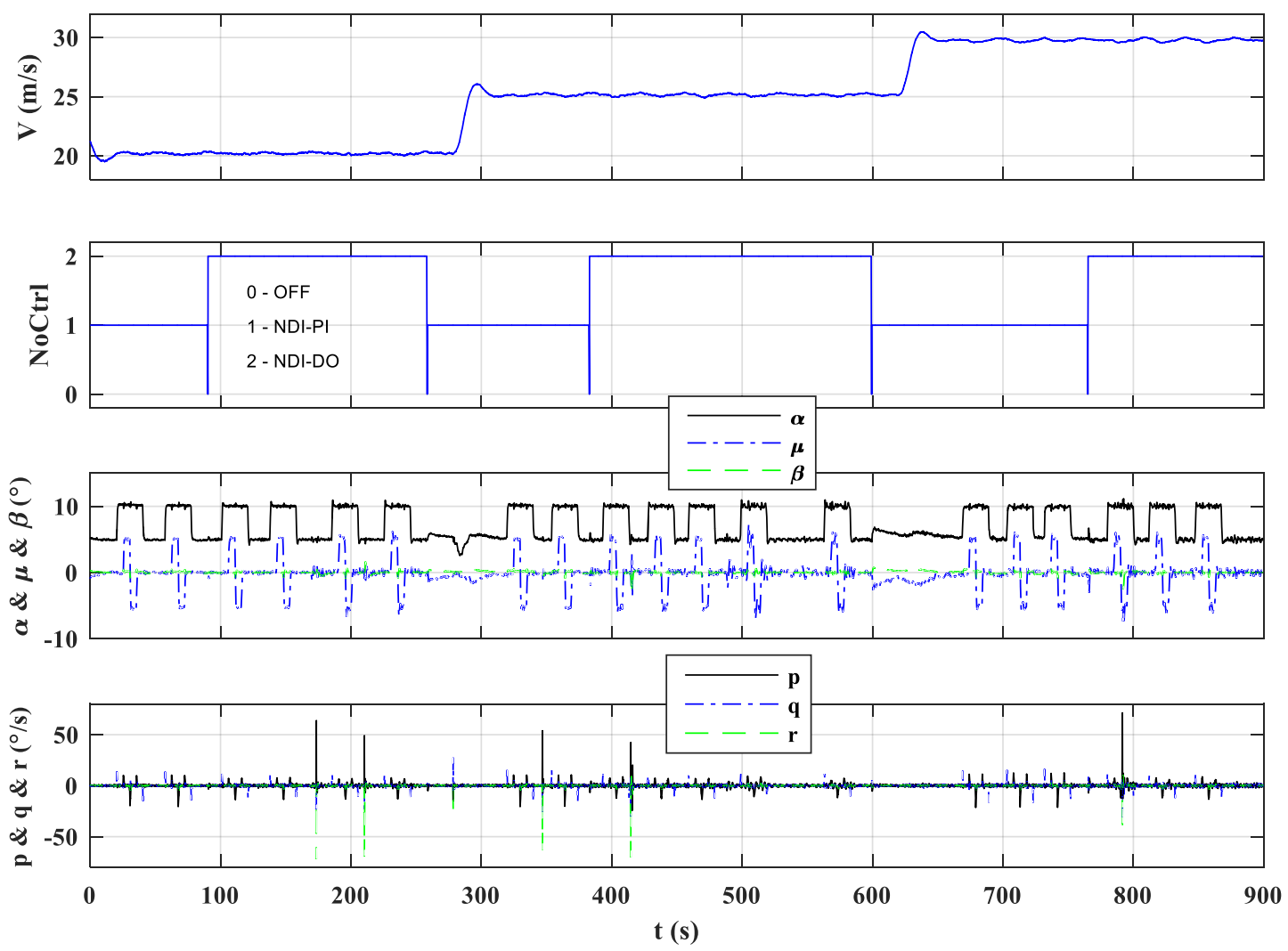

Figure 10. Experimental results of the tailless aircraft model controlled using NDI-PI and NDI-DO in the wind tunnel flight tests.

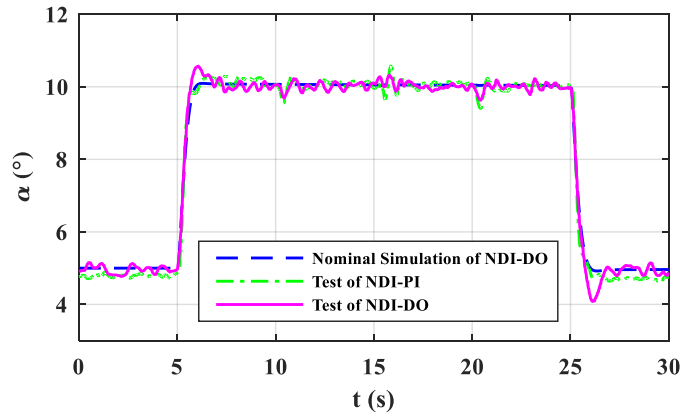

(a) Angle of attack

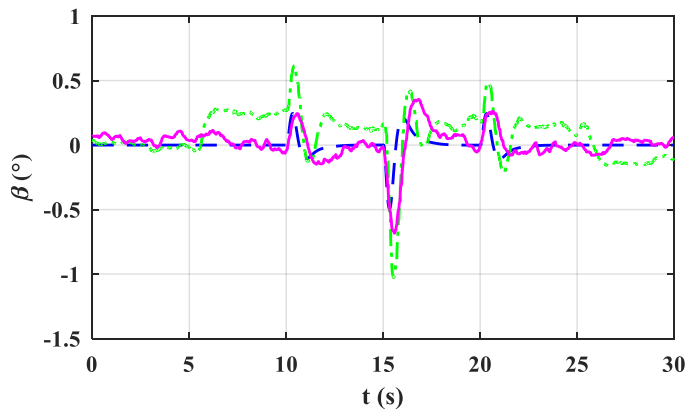

(c) Angle of sideslip

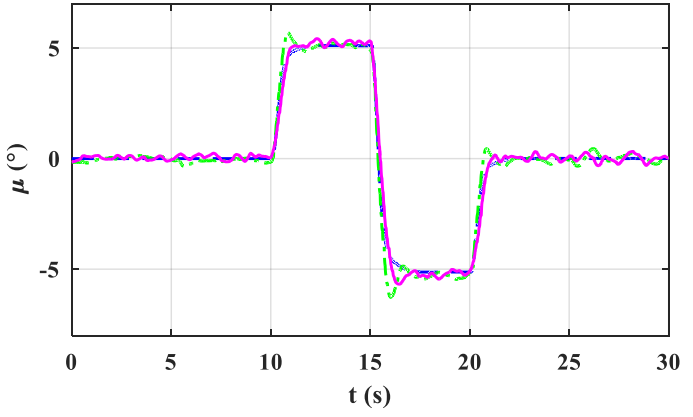

(b) Bank angle about the velocity vector

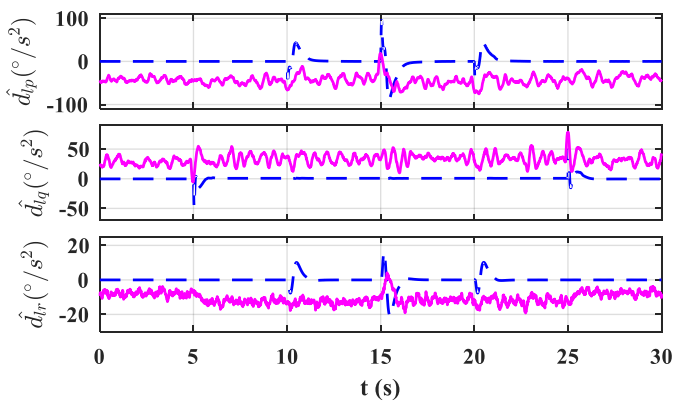

(d) Estimation of the lumped disturbances

Figure 11. Experimental responses of the tailless aircraft model controlled using NDI-PI and NDI-DO in the wind tunnel flight tests in contrast with the nominal simulation results of NDI-DO. 


\section{Conclusions}

In this paper, the dynamic inversion based disturbance rejection control schemes were designed and subsequent flight tests in the wind tunnel were carried out for a tailless aircraft model. An overview of the aircraft model and the experimental setup was provided. A comprehensive nonlinear mathematical model related to the flight dynamics of the aircraft model supported with a 3-DOF rig in the wind tunnel was derived and then rewritten in the form of a nonlinear affine system. A baseline NDI controller was designed to stabilize and control the aircraft attitude, which was further augmented with a disturbance observer to reject the lumped disturbances. In the presence of actuator saturation, an anti-windup modification was made to the disturbance observer. The simulation results show that the robustness of the disturbance observer augmented controllers was superior to the baseline NDI controller, and the anti-windup modified disturbance observer helped to recover the control performance from the actuator saturation. Finally, flight tests were successfully conducted in the wind tunnel setup showing that the experimental results agreed well with the simulations under the control of the NDI-DO scheme, which demonstrated superior tracking and robust performance than the NDI-PI scheme. However, the NDI-AW controller was not implemented and tested due to the absence of sensors for the actual surface deflections.

To the authors' knowledge, this is the first realistic tailless aircraft model application and real-time implementation of the NDI-DO scheme to validate the effectiveness of the disturbance rejection NDI control method in the wind tunnel. It is shown that the NDI-DO scheme performed better than the NDI-PI scheme in the presence of high-level disturbances. The NDI-AW scheme shows the prospective closed-loop performance recovering from the actuator saturations, which will be implemented and validated via the wind-tunnel flight tests in the future.

Author Contributions: Supervision, H.M. and O.S.; Writing-Original draft, B.N.; Writing-Review and editing, Z.L., T.G. and L.F. All authors have read and agreed to the published version of the manuscript.

Funding: This research received no external funding.

Institutional Review Board Statement: Not applicable.

Informed Consent Statement: Not applicable.

Data Availability Statement: The data presented in this study are available on request from the corresponding author.

Conflicts of Interest: The authors declare no conflict of interest.

\section{References}

1. Colgren, R.; Loschke, R. Effective design of highly maneuverable tailless aircraft. J. Aircr. 2008, 45, 1441-1449. [CrossRef]

2. Friehmelt, H. Thrust vectoring and tailless aircraft design-Review and outlook. In Proceedings of the 21st Atmospheric Flight Mechanics Conference, San Diego, CA, USA, 29-31 July 1996; pp. 420-430.

3. Bowlus, J.; Multhopp, D.; Banda, S.; Bowlus, J.; Multhopp, D.; Banda, S. Challenges and opportunities in tailless aircraft stability and control. In Guidance, Navigation, and Control Conference; American Institute of Aeronautics and Astronautics: Boston, MA, USA, 1997; pp. 1713-1718.

4. Wise, K. Fighter Aircraft Control Challenges and Technology Transition. In Systems and Control in the Twenty-First Century; Birkhäuser: Boston, MA, USA, 1997; pp. 417-434. ISBN 978-1-4612-8662-2.

5. Stenfelt, G.; Ringertz, U. Yaw control of a tailless aircraft configuration. J. Aircr. 2010, 47, 1807-1811. [CrossRef]

6. Stenfelt, G.; Ringertz, U. Yaw departure and recovery of a tailless aircraft configuration. J. Aircr. 2013, 50, 311-315. [CrossRef]

7. Wells, S.R.; Hess, R.A. Multi-Input/Multi-Output Sliding Mode Control for a Tailless Fighter Aircraft. J. Guid. Control. Dyn. 2003, 26, 463-473. [CrossRef]

8. Ngo, A.; Reigelsperger, W.; Banda, S.; Bessolo, J. Multivariable control law design for a tailless airplane. In Proceedings of the Guidance, Navigation, and Control Conference, San Diego, CA, USA, 29-31 July 1996; pp. 1-11.

9. Buffington, J. Modular Control. Law Design for the Innovative Control. Effectors (ICE) Tailless Fighter Aircraft Configuration 101-3; AFRL-VA-WP-TP-1999-3057; U.S. Air Force Research Lab.: Wright-Patterson Air Force Base, OH, USA, June 1999.

10. Wise, K.; Sedwick, J.; Ikeda, Y. Nonlinear Control. of Fighter Aircraft; F49620-96-C-0011; The Boeing Company: St. Louis, MO, USA, June 1999. 
11. Jackson, E.B.; Buttrill, C.W. Control. Laws for a Wind Tunnel Free-Flight Study of a Blended-Wing-Body Aircraft; TM-2006-214501; NASA: Hampton, VA, USA, 2006.

12. Cook, M.V.; Castro, H.V. The longitudinal flying qualities of a blended-wing-body civil transport aircraft. Aeronaut. J. 2004, 108, 75-84. [CrossRef]

13. Nieto-Wire, C.; Sobel, K. Delta Operator Eigenstructure Assignment for Reconfigurable Control of a Tailless Aircraft. J. Guid. Control. Dyn. 2014, 37, 1824-1839. [CrossRef]

14. Calise, A.; Lee, S.; Sharma, M. Direct adaptive reconfigurable control of a tailless fighter aircraft. In Proceedings of the Guidance, Navigation, and Control Conference and Exhibit, Boston, MA, USA, 10-12 August 1998.

15. Brinker, J.; Wise, K. Reconfigurable flight control for a tailless advanced fighter aircraft. In Proceedings of the Guidance, Navigation, and Control Conference and Exhibit, Boston, MA, USA, 10-12 August 1998.

16. Calise, A.J.; Lee, S.; Sharma, M. Development of a Reconfigurable Flight Control Law for Tailless Aircraft. J. Guid. Control. Dyn. 2001, 24, 896-902. [CrossRef]

17. Brinker, J.S.; Wise, K.A. Flight Testing of Reconfigurable Control Law on the X-36 Tailless Aircraft. J. Guid. Control. Dyn. 2001, 24, 903-909. [CrossRef]

18. Jones, C.; Lowenberg, M.; Richardson, T. Dynamic State-Feedback Gain Scheduled Control of the ICE 101-TV. In Proceedings of the AIAA Guidance, Navigation, and Control Conference and Exhibit, Providence, RI, USA, 16-19 August 2004.

19. Huber, P. Control law design for tailless configurations and in-flight simulation using the X-31 aircraft. In Proceedings of the Guidance, Navigation, and Control Conference, Baltimore, MD, USA, 7-10 August 1995.

20. Balas, G.J. Flight Control Law Design: An Industry Perspective. Eur. J. Control. 2003, 9, 207-226. [CrossRef]

21. Enns, D.; Bugajski, D.; Hendrick, R.; Stein, G. Dynamic inversion: An evolving methodology for flight control design. Int. J. Control. 1994, 59, 71-91. [CrossRef]

22. Wang, X.; van Kampen, E.-J.; Chu, Q.; Lu, P. Stability Analysis for Incremental Nonlinear Dynamic Inversion Control. J. Guid. Control. Dyn. 2019, 42, 1116-1129. [CrossRef]

23. Safwat, E.; Zhang, W.; Mohsen, A. Design and Analysis of a Robust UAV Flight Guidance and Control System Based on a Modified Nonlinear Dynamic Inversion. Appl. Sci. 2019, 9, 3600. [CrossRef]

24. Vicroy, D.D.; Loeser, T.D.; Schütte, A. Static and forced-oscillation tests of a generic unmanned combat air vehicle. J. Aircr. 2012, 49, 1558-1583. [CrossRef]

25. Smith, J.; su, J.; Liu, C.; Chen, W.-H. Disturbance Observer Based Control with Anti-Windup Applied to a Small Fixed Wing UAV for Disturbance Rejection. J. Intell. Robot. Syst. 2017, 88, 329-346. [CrossRef]

26. Ding, S.; Chen, W.; Mei, K.; Murray-Smith, D.J. Disturbance Observer Design for Nonlinear Systems Represented by Input-Output Models. IEEE Trans. Ind. Electron. 2020, 67, 1222-1232. [CrossRef]

27. An, H.; Wu, Q. Disturbance rejection dynamic inverse control of air-breathing hypersonic vehicles. Acta Astronaut. 2018, 151, 348-356. [CrossRef]

28. Yang, J.; Zolotas, A.; Chen, W.-H.; Michail, K.; Li, S. Robust control of nonlinear MAGLEV suspension system with mismatched uncertainties via DOBC approach. ISA Trans. 2011, 50, 389-396. [CrossRef]

29. Chen, W.-H.; Ballance, D.J.; Gawthrop, P.J.; O'Reilly, J. A nonlinear disturbance observer for robotic manipulators. IEEE Trans. Ind. Electron. 2000, 47, 932-938. [CrossRef]

30. Chen, W.-H. Nonlinear Disturbance Observer-Enhanced Dynamic Inversion Control of Missiles. J. Guid. Control. Dyn. 2003, 26, 161-166. [CrossRef]

31. Sun, L.; Zheng, Z. Disturbance Observer-Based Robust Saturated Control for Spacecraft Proximity Maneuvers. IEEE Trans. Control. Syst. Technol. 2018, 26, 684-692. [CrossRef]

32. Chen, Z.; Sun, C.; Cen, F.; Nie, B.; Li, Q. Disturbance observer based dynamic inversion control for a wind tunnel free-flying test of a blended-wing-body aircraft. In Proceedings of the 2019 Chinese Automation Congress, Hangzhou, China, 22-24 November 2019.

33. Valasek, J.; Ito, D.; Ward, D. Robust dynamic inversion controller design and analysis for the X-38. In Proceedings of the AIAA Guidance, Navigation, and Control Conference and Exhibit, Montreal, QC, Canada, 6-9 August 2001.

34. Menon, P.P.; Lowenberg, M.; Herrmann, G.; Turner, M.C.; Bates, D.G.; Postlethwaite, I. Experimental Implementation of a Nonlinear Dynamic Inversion Controller with Antiwindup. J. Guid. Control. Dyn. 2013, 36, 1035-1046. [CrossRef]

35. Herrmann, G.; Menon, P.P.; Turner, M.C.; Bates, D.G.; Postlethwaite, I. Anti-windup synthesis for nonlinear dynamic inversion control schemes. Int. J. Robust Nonlinear Control. 2010, 20, 1465-1482. [CrossRef]

36. Nie, B.; Liu, Z.; Cen, F.; Liu, D.; Ma, H.; Sename, O. An Innovative Experimental Approach to Lateral-Directional Flying Quality Investigation for Tailless Aircraft. IEEE Access 2020, 8, 109543-109556. [CrossRef]

37. Chen, Z.; Li, Q.; Ju, X.; Cen, F. Barrier Lyapunov Function based Sliding Mode Control for BWB Aircraft with Mismatched Disturbances and Output Constraints. IEEE Access 2019, 1. [CrossRef]

38. Stevens, B.L.; Lewis, F.L.; Johnson, E.N. Aircraft Control and Simulation: Dynamics, Controls Design, and Autonomous Systems, 3rd ed.; Wiley: Hoboken, NJ, USA, 2016.

39. Juliana, S.; Chu, Q.P.; Mulder, J.A.; van Baten, T.J. Flight Control of Atmospheric Re-entry Vehicle with Non-linear Dynamic Inversion. In Proceedings of the AIAA Guidance, Navigation, and Control Conference and Exhibit, Providence, RI, USA, 16-19 August 2004. 
40. Snell, S.A.; Enns, D.F.; Garrard, W.L. Nonlinear inversion flight control for a supermaneuverable aircraft. J. Guid. Control. Dyn. 1992, 15, 976-984. [CrossRef]

41. Lane, S.H.; Stengel, R.F. Flight control design using non-linear inverse dynamics. Automatica 1988, 24, 471-483. [CrossRef]

42. Hedrick, J.K.; Gopalswamy, S. Nonlinear flight control design via sliding methods. J. Guid. Control. Dyn. 1990, 13, 850-858. [CrossRef]

43. Sieberling, S.; Chu, Q.P.; Mulder, J.A. Robust Flight Control Using Incremental Nonlinear Dynamic Inversion and Angular Acceleration Prediction. J. Guid. Control Dyn. 2010, 33, 1732-1742. [CrossRef]

44. Adams, R.J.; Buffington, J.M.; Banda, S.S. Design of nonlinear control laws for high-angle-of-attack flight. J. Guid. Control Dyn. 1994, 17, 737-746. [CrossRef]

45. Bugajski, D.J.; Enns, D.F. Nonlinear control law with application to high angle-of-attack flight. J. Guid. Control Dyn. 1992, 15, 761-767. [CrossRef]

46. da Costa, R.R.; Chu, Q.P.; Mulder, J.A. Reentry flight controller design using nonlinear dynamic inversion. J. Spacecr. Rockets 2003, 40, 64-71. [CrossRef]

47. Yang, J.; Li, S.; Chen, W.-H. Nonlinear Disturbance Observer-Based Control for Multi-Input Multi-Output Nonlinear Systems Subject to Mismatching Condition; Taylor \& Francis: Abingdon, UK, 2012; Volume 85.

48. Rehman, O.U.; Fidan, B.; Petersen, I.R. Uncertainty modeling and robust minimax LQR control of multivariable nonlinear systems with application to hypersonic flight. Asian J. Control. 2012, 14, 1180-1193. [CrossRef]

49. Wang, Q.; Stengel, R.F. Robust Nonlinear Control of a Hypersonic Aircraft. J. Guid. Control. Dyn. 2000, 23, 577-585. [CrossRef]

50. Chen, W.H.; Ballance, D.J.; Gawthrop, P.J.; Gribble, J.J.; O’Reilly, J. Nonlinear PID predictive controller. IEE Proc. Control. Theory Appl. 1999, 146, 603-611. [CrossRef]

51. Khalil, H.K.; Grizzle, J.W. Nonlinear Systems, 3rd ed.; Prentice Hall: Upper Saddle River, NJ, USA, $2002 ;$ ISBN 0130673897. 